\title{
Records of Parochlus steinenii in the Maritime Antarctic and sub-Antarctic regions
}

\author{
Melisa Gañan ${ }^{1,3}$, Tamara Contador ${ }^{1,2,3}$, Javier Rendoll ${ }^{1,2}$, Felipe Simoes ${ }^{4,5}$, \\ Carolina Pérez ${ }^{1,2}$, Gillian Graham ${ }^{6}$, Simón Castillo ${ }^{7}$, James Kennedy ${ }^{1,2,6}$, Peter Convey ${ }^{4}$ \\ I Wankara Sub-Antarctic and Antarctic Freshwater Ecosystems Laboratory, Sub-Antarctic Biocultural, Con- \\ servation Program, Universidad de Magallanes, Puerto Williams, Teniente Muñoz 166, Chile 2 Institute of \\ Ecology and Biodiversity, Universidad de Chile, Santiago, Las Palmeras 3425, Chile 3 Núcleo Milenio de \\ Salmónidos Invasores (INVASAL) Iniciativa Cientifica Milenio, ICM, Núcleo Científico Milenio, Concepción, \\ Chile 4 British Antarctic Survey, NERC, High Cross, Madingley Road, Cambridge CB3 OET, UK 5 Depart- \\ ment of Zoology, Museum of Zoology, University of Cambridge, Downing Street, Cambridge CB2 3EJ, UK \\ 6 Department of Biological Sciences, University of North Texas, 1511 W Sycamore, Denton, TX 76201, USA \\ 7 Department of Ecology, Pontificia Universidad Católica, Facultad de Ciencias Biológicas. Avda. Libertador \\ Bernardo O'Higgins 340, Santiago, Chile
}

Corresponding author: Melisa Gañan (melysa_gm@yahoo.es); Tamara Contador (tamara.contador@umag.cl)

Academic editor: F. Laurindo da Silva | Received 23 July 2020 | Accepted 7 October 2020 | Published 18 January 2021

http://zoobank.org/BC17D44D-A149-4453-845E-9C909CCC35E8

Citation: Gañan M, Contador T, Rendoll J, Simoes F, Pérez C, Graham G, Castillo S, Kennedy J, Convey P (2021) Records of Parochlus steinenii in the Maritime Antarctic and sub-Antarctic regions. ZooKeys 1011: 63-71. https://doi. org/10.3897/zookeys.1011.56833

\begin{abstract}
This study provides the summary of the reports of the geographical distribution in the Maritime Antarctic and sub-Antarctic regions of Parochlus steinenii (Gercke, 1889) (Diptera, Chironomidae), the only flying insect occurring naturally in the Antarctic continent. The distribution encompasses the South Shetland Islands (Maritime Antarctic), South Georgia (sub-Antarctic), and parts of the Cape Horn Biosphere Reserve (CHBR, southern Chile). In total 78 occurrence records were identified, 53 from our own records, 19 from the literature, and six from other data present in GBIF. Of the 78 records, 66 are from the South Shetland Islands, eight are from South Georgia, and four from the CHBR. This database was developed as one of the main objectives of two Chilean-funded research projects addressing understanding the effects of climate change on sub-Antarctic and Antarctic insects. It provides dataset documenting the distribution of Parochlus steinenii in the Maritime Antarctic, the sub-Antarctic, and the CHBR in southern South America (Chile). The complete dataset is available in Darwin Core Archive format via the Global Biodiversity Information Facility (GBIF).
\end{abstract}

Copyright Melisa Gañan et al. This is an open access article distributed under the terms of the Creative Commons Attribution License (CC BY 4.0), which permits unrestricted use, distribution, and reproduction in any medium, provided the original author and source are credited. 


\section{Keywords}

Cape Horn Biosphere Reserve, Parochlus steinenii, South Georgia, South Shetland Islands, winged Antarctic midge

\section{Project details}

Project title: This database was developed as part of the main objectives of two Chilean-funded research projects aiming towards better understanding the effects of climate change in sub-Antarctic and Antarctic insects:

- Dipterans in sub-Antarctic and Antarctic regions: are they ready for the changes?

- Addressing global warming scenarios in freshwater ecosystems using aquatic insects as model organisms in the Magellanic sub-Antarctic and Antarctic regions.

Personnel: Melisa Gañan (Data Collector, Data Manager, Data Publisher), Tamara Contador (Principal Investigator, Data Collector, Data Manager, Data Publisher), Javier Rendoll (Data Collector, Data Manager), Felipe Simoes (Data Collector, Data Manager), Carolina Pérez (Data Collector, Data Manager), Gillian Graham (Data Collector), Simón Castillo (Data Collector), James Kennedy (Data Collector, Data Manager) and Peter Convey (Data Collector, Data Manager).

Funding: INACH RT-48_16 and Fondecyt de Iniciación 11130451.

Study area descriptions/descriptor: The study area (Fig. 1) includes: 1 . The South Shetland Islands and part of the north-west coast of the Antarctic Peninsula (Antarctic Conservation Biogeographic Region (ACBR) 3, Terauds et al. 2012; Terauds and Lee 2016); 2. The sub-Antarctic island of South Georgia; 3. Navarino Island, Cape Horn National Park, and Diego Ramírez Marine Park (Cape Horn Biosphere Reserve, Magallanes sub-Antarctic region, Rozzi et al. 2012).

Design description: The study was conducted throughout the latitudinal and environmental gradient that includes the southern tip of South America in the subAntarctic Magellanic ecoregion $\left(54-57^{\circ} \mathrm{S}\right)$, and the Scotia Arc distribution of Parochlus steinenii (P. steinenii) in the sub-Antarctic (South Georgia, 53-54 ${ }^{\circ} \mathrm{S}$ ) and Maritime Antarctic (South Shetland Islands, $63-64^{\circ} \mathrm{S}$ ) regions. The geographical range of the study involves both small-scale (microhabitats and environmental gradients) and the larger spatial scale 10-degree latitudinal gradient.

The specific locations surveyed were: 1. On the maritime Antarctic South Shetland Islands, ice-free areas on Deception, Livingston, Greenwich, Robert, Nelson, King George Islands, and the north-west coast of Antarctic Peninsula (Trinity Peninsula and Litchfield Island). These areas are characterized by a geomorphology which includes periglacial landforms, with numerous temporary shallow meltwater ponds and permanent lakes (typically smaller than $100 \mathrm{~m}^{2}$ ), which are ice-covered for 9-10 months of the year (Contador et al. 2020); 2. In South Georgia, which is the largest island on the Scotia 

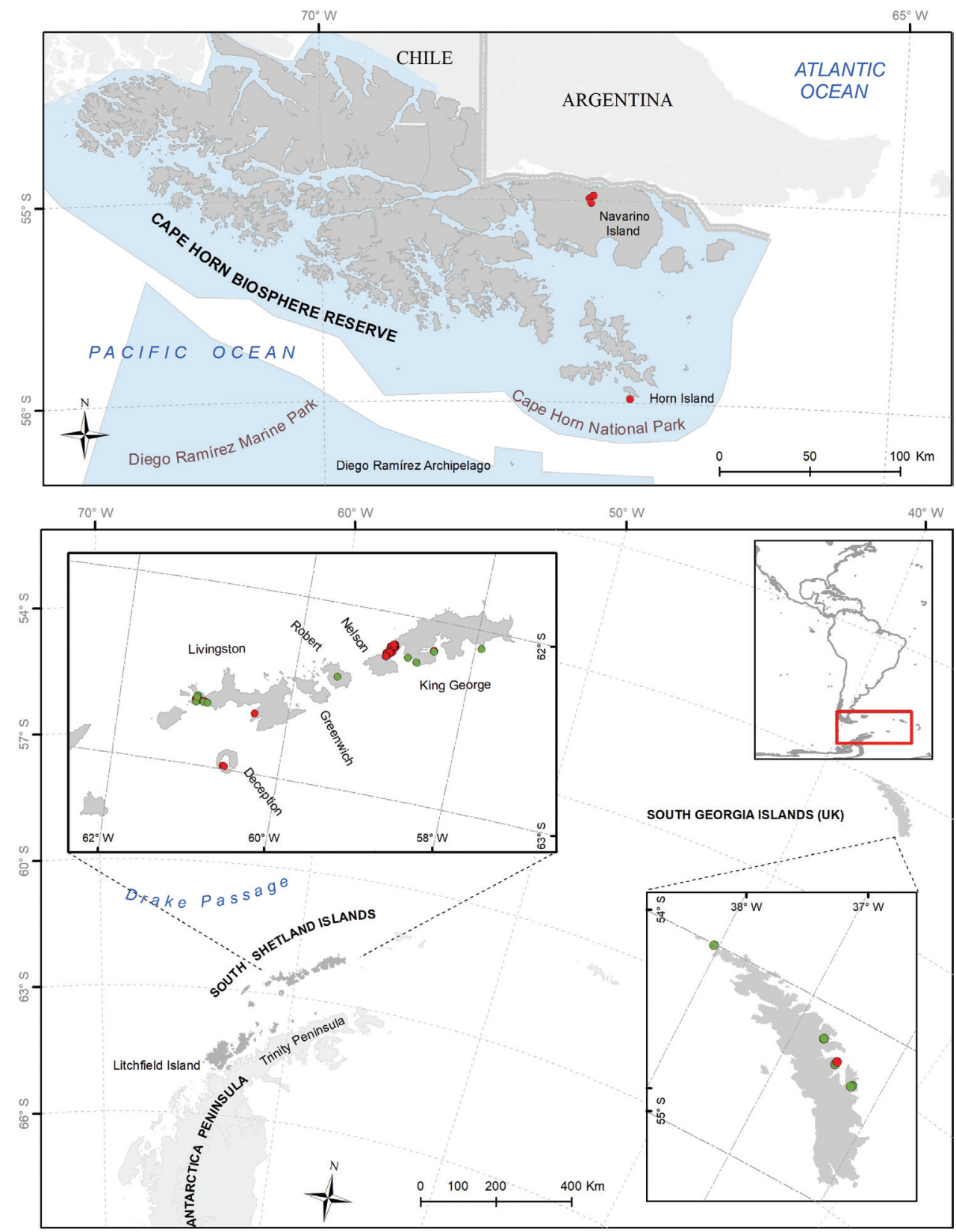

Figure I. Map of study area. The red circles correspond to the records of Parochlus steinenii found in this study, the green circles correspond to the bibliographic records.

Arc, with much of the barren, mountainous and highly glacial territory (Regional ecosystem profile - Polar and Sub-polar Region 2017), we surveyed accessible lakes near the British Antarctic Survey research station; 3. In CHBR, we surveyed the north coast of 
Navarino Island, with freshwater systems that present altitudinal gradients with marked slopes in an altitudinal range that extends between $1000 \mathrm{~m}$ and sea level, and where the thermal ranges change drastically along of the altitudinal profile (Contador 2011; Contador et al. 2015). We also surveyed Horn Island in the southernmost of the Cape Horn archipelago, and the Diego Ramirez archipelago, both made up of low-lying islets and marked by strong winds throughout the year (Pisano 1980, Pisano and Schlatter 1981).

Field expeditions were organized by the Chilean Antarctic Institute (INACH) in South Shetland Islands; by the British Antarctic Survey in South Georgia; and by the SubAntarctic Biocultural Conservation Program of the Universidad de Magallanes in CHBR.

\section{Taxonomic coverage}

General taxonomic coverage description: The dataset reports occurrences of the species Parochlus steinenii (Gercke, 1889) (Diptera: Chironomidae: Podonominae), also known as the winged Antarctic midge. P. steinenii is recorded from freshwater ecosystems through the ice-free areas of the South Shetland Islands in the Maritime Antarctic, on sub-Antarctic South Georgia, and in Navarino and Horn islands in the CHBR. Knowing these presences is of great importance since $P$. steinenii has been proposed as an effective native sentinel species and indicator of climate change in Antarctica (Contador et al. 2020).

\section{Taxonomic ranks}

Kingdom Animalia

Phylum Arthropoda

Class Insecta

Order Diptera

Family Chironomidae

Subfamily Podonominae

Tribe Podonomini

Genus Parochlus

Species Parochlus steinenii

Common name: winged Antarctic midge

\section{Spatial coverage}

General spatial coverage: The dataset comprises the South Shetland Islands, specifically King George, Nelson, Robert, Livingston and Deception islands in the Maritime Antarctic, South Georgia in the sub-Antarctic, and Horn and Navarino islands in the CHBR (southern South America, Chile).

Coordinates: The areas surveyed lie within the polygon $53-63^{\circ} \mathrm{S}$ latitude and 35-69 $\mathrm{W}$ longitude. 


\section{Temporal coverage}

January 1, 2014-February 25, 2019.

\section{Natural collections description}

Parent collection identifier: UMAG: WANKARA LABORATORY

Collection name: Colección de Invertebrados Antárticos y Subantárticos del Laboratorio Dulceacuícola Wankara de la Universidad de Magallanes, Puerto Williams

Collection identifier: urn:UMAG:WANKARA:Inv:Dip:AQ:Pstei and urn:UMA G:WANKARA:Inv:Dip:CL:Pstei

Specimen preservation method: $95 \%$ alcohol

Curatorial unit: 20 individuals per $5 \mathrm{ml}$ glass vials

\section{Methods}

Survey and sampling: Intensive field surveys through accessible ice-free areas in the South Shetland Islands, through lakes on South Georgia, and lakes on Horn Island, Navarino Island, and Diego Ramírez archipelago were conducted. For each sample site, the presence of $P$. steinenii was assessed and reference collection of individuals was made, the macrohabitat was described, and the climatic and water variables were recorded. Survey data were combined with information from a careful bibliographic review.

Sampling description: All sites were sampled for a period of 4-6 h, depending on climatic conditions and logistic support. We assessed the presence of P. steinenii as larvae, pupae, or adults by searching close to the shoreline of lakes and streams, and specifically under rocks and vegetation, and in sediments (Fig. 2). We manually extracted specimens from rocks and mosses and sometimes with the use of an entomological aspirator. Each site visited was georeferenced using a Garmin 78SC GPS receiver. Water body typology and macrohabitat were described following Hahn and Reinhardt (2006). Climatic variables (air temperature, wind speed, and relative humidity) were measured using an anemometer (Kestrel 3000 Env) and water variables (pH, conductivity, water temperature, and dissolved oxygen) were measured using a YSI 605 595 Professional Plus multimeter. We additionally sourced all available information from the existing literature (see Torres 1956; Wirth and Gressitt 1967; Brundin 1970; Edwars and Usher 1985; Rauschert 1985; Shimada et al. 1991; Richard et al. 1994; Convey and Block 1996; Allegrucci et al. 2006; Hahn and Reinhardt 2006; Toro et al. 2006; Agius et al. 2008; Rico and Quesada 2013).

Fieldwork in the Antarctic was conducted during six austral summer seasons (2013/14, 2014/15, 2015/16, 2016/17, 2017/18 and 2018/19). In South Georgia fieldwork was conducted in the Austral summer of 2018 and in the Magellanic subAntarctic Region in the Austral summer of 2016. 


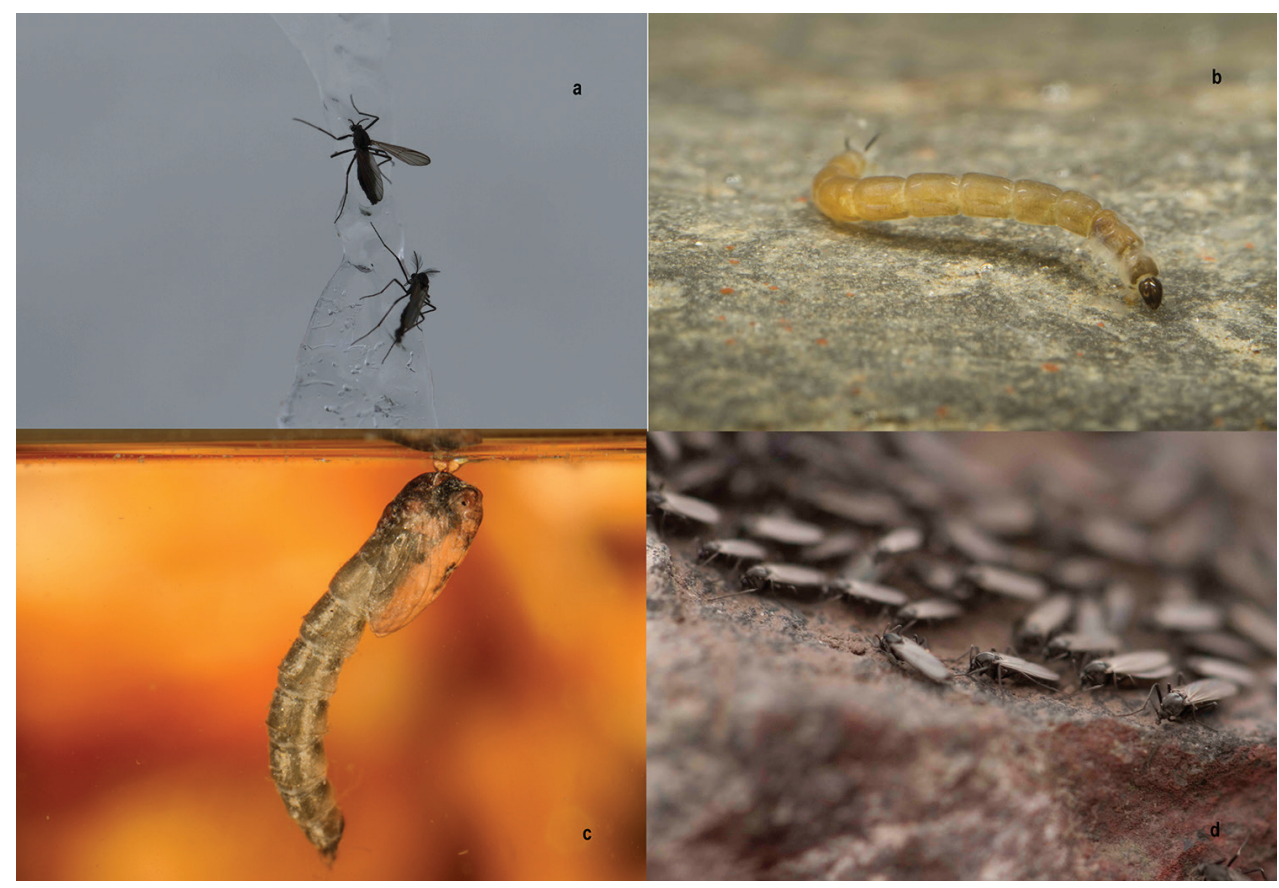

Figure 2. Parochlus steinenii (Fildes Bay, South Shetland Islands). a Female (up) and male (down) adult b larva $\mathbf{c}$ pupa $\mathbf{d}$ group of adults on a stone.

Living individuals were transported to the laboratory for phenology and physiologic studies, while some individuals were immediately preserved in alcohol (95\%) for genetic studies. Samples were transported to the Wankara Subantarctic and Antarctic Freshwater Studies Laboratory at Magallanes University in Puerto Williams, Chile. Characteristics of the species according to the taxonomic key of Wirth and Gressitt (1967) were verified in the laboratory. To date, the species was not recorded in any extensive terrestrial/freshwater study along the Diego Ramírez Island, South Orkney Islands, or north-west coast of the Antarctic Peninsula (Chown and Convey 2016; Contador et al. 2020).

Quality control description: Each record of the species obtained in the field was georeferenced using a Garmin 78SC GPS receiver. Most records obtained from literature included geographical coordinates. Otherwise, we assigned a georeference record by identification of the body of water described in the study.

Geographic names used for records presented here follow the official name used in the maps prepared by the SCAR Composite Gazetteer of Antarctica (CGA) and by the Military Geographical Institute (IGM) of Chile. For sites lacking formal names, unofficial names were assigned.

Data resources: The data set of this article is deposited at GBIF, the Global Biodiversity Information Facility, https://www.gbif.org/dataset/30c49fbf-4e2e-482e-bb494d294bc332cb, https://doi.org/10.15468/2cfwd7. 


\section{Datasets}

Dataset description

Object name: Darwin Core Archive Presence Parochlus steinenii AQ_CL Character encoding: UTF-8

Format name: Darwin Core Archive format

Format version: 1.0

Distribution: https://www.gbif.org/dataset/30c49fbf-4e2e-482e-bb49-4d294bc332cb

Publication date of data: 2020-05-27

Language: English

Licenses of use: Creative Commons Attribution (CC-BY) 4.0 License

Metadata language: English

Date of metadata creation: 2020-05-27

Hierarchy level: Dataset

\section{Acknowledgements}

This project was funded by Chile's National Fund for Scientific and Technological Development (FONDECYT), the Chilean Antarctic Institute (INACH), and CONICYT PIA Apoyo CCTE (projects 11130451, RT_48_16, and AFB170008, respectively). Felipe was funded by Conselho Nacional de Desenvolvimento Científico e Tecnológico and the Cambridge Trust, PhD scholarship Process no. 233923/2014-4.

Peter C. was supported by NERC core funding to the British Antarctic Survey (BAS) "Biodiversity Evolution and Adaptation" Team. Gonzalo Arriagada produced the photographs of Parochlus steinenii larvae, pupae and adults used in Fig. 2. In Fig. 1, coastline_high_res_line, and seamask_high_res_polygon layers were downloaded from the Antarctic Digital Database (ADD version 7; http://www.add.scar.org).

\section{References}

Agius J, Gibson J, Rico E, Quesada A (2009) Paleolimnological evidence confirms that Parochlus steinenii (Gerke) is not a recent introduction to the Antarctic Peninsula Region. Chironomus Newsletter of Chironomidae Research 22: 18-21. https://doi.org/10.5324/cjcr.v0i22.604 Allegrucci G, Carchini G, Todisco V, Convey P, Sbordoni V (2006) A molecular phylogeny of Antarctic Chironomidae and its implications for biogeographical history. Polar Biology 29: 320-326. https://doi.org/10.1007/s00300-005-0056-7

Brundin L (1970) Diptera: Chironomidae of South Georgia. Pacific Insects Monograph 23: 276-276. 
Chown SL, Convey P (2016) Antarctic entomology. Annual Review of Entomology 61: 119-137. https://doi.org/10.1146/annurev-ento-010715-023537

Contador T (2011) Benthic macroinvertebrates of temperate, sub-Antarctic streams: the effects of altitudinal zoning and temperature on the phenology of aquatic insects associated to the Róbalo river, Navarino Island $\left(55^{\circ} \mathrm{S}\right)$, Chile. PhD Thesis. University of North Texas, Denton, $140 \mathrm{pp}$.

Contador T, Kennedy JH, Rozzi R, Villarroel JO (2015) Sharp altitudinal gradients in Magellanic Sub-Antarctic streams: patterns along a fluvial system in the Cape Horn Biosphere Reserve (55'S). Polar Biology 38: 1853-1866. https://doi.org/10.1007/s00300-015-1746-4

Contador T, Gañan M, Bizama G, Fuentes-Jaque G, Morales L, Rendoll J, Simoes F, Kennedy J, Rozzi R, Convey P (2020) Assessing distribution shifts and ecophysiological characteristics of the only Antarctic winged midge under climate change scenarios. Scientific Reports 10: e9087. https://doi.org/10.1038/s41598-020-65571-3

Convey P, Block W (1996) Antarctic Diptera: ecology, physiology and distribution. European Journal of Entomology 93: 1-13.

Edwards M, Usher MB (1985) The windged Antarctic midge Parochlus steinenii (Gerke) (Diptera: Chironomidae) in the South Shetland Islands. Biological Journal of the Linnean Society 26: 83-93. https://doi.org/10.1111/j.1095-8312.1985.tb01553.x

Hahn S, Reinhardt K (2006) Habitat preference and reproductive traits in the Antarctic midge Parochlus steinenii (Diptera: Chironomidae). Antarctic Science 18: 175-181. https://doi. org/10.1017/S0954102006000204

Pisano E (1980) Catálogo de la flora vascular del archipiélago del Cabo de Hornos. Anales Del Instituto de La Patagonia (Chile) 11: 151-189.

Pisano E, Schlatter R (1981) Vegetación y flora de las islas Diego Ramirez (Chile). I. Características y Relaciones de la flora vascular. Anales del Instituto de La Patagonia 12: 183-194.

Rauschert M (1985) Beobachtungen an der Chironomide Parochlus steinenii auf der Insel King George (Südshetlandinseln, Antarktis) (Diptera, Chironomidae). Deutsche Entomologische Zeitschrift 32: 183-188. https://doi.org/10.1002/mmnd.19850320125

Regional ecosystem profile - Polar and Sub-polar Region (2017) EU Outermost Regions and Overseas Countries and Territories, Claire-Sophie Azam, Cédric Marteau, Vincent Piton, Cynthia Borot, Paul Tixier. Terres australes et antarctiques françaises (TAAF). BEST, Service contract 07.0307.2013/666363/SER/B2, European Commission, 225 pp. [+ 31 Annexes, 24-27]

Richard KJ, Convey P, Block W (1994) The terrestrial arthropod fauna of the Byers Peninsula, Livingston Island, South Shetland Islands. Polar Biology 14: 371-379. https://doi. org/10.1007/BF00240257

Rico E, Quesada A (2013) Distribution and ecology of chironomids (Diptera, Chironomidae) on Byers Peninsula, Maritime Antarctica. Antarctic Science 25: 288-291. https://doi. org/10.1017/S095410201200096X

Rozzi R, Armesto JJ, Gutiérrez J, Massardo F, Likens G, Anderson CB, Poole A, Moses K, Hargrove G, Mansilla A, Kennedy JH, Willson M, Jax K, Jones C, Callicott JB, Kalin MT (2012) Integrating ecology and environmental ethics: Earth stewardship in the southern end of the Americas. BioScience 62: 226-236. https://doi.org/10.1525/bio.2012.62.3.4 
Shimada K, Ohyama Y, Pan CX (1991) Cold-hardiness of the Antarctic winged midge Parochlus steineni during the active season at King George Island. Polar Biology 11: 311-314. https://doi.org/10.1007/BF00239023

Simóes F (2019) Ecophysiology, morphology and phylogeography of insects in the Scotia Arc. PhD Thesis. University of Cambridge, Cambridge, $191 \mathrm{pp}$.

Terauds A, Chown S, Morgan F, Peat J, Watts D, Keys H, Convey P, Bergstrom D (2012) Conservation biogeography of the Antarctic. Diversity and Distributions 18: 726-741. https:// doi.org/10.1111/j.1472-4642.2012.00925.x

Terauds A, Lee JR (2016) Antarctic biogeography revisited: updating the Antarctic Conservation Biogeographic Regions. Diversity and Distributions 22: 836-840. https://doi. org/10.1111/ddi.12453

Torres BA (1956) Primer hallazgo de Tendipedidos alados en la región Antártica. Podonominae, una nueva subfamilia para la citada región. Anales de la Sociedad Científica Argentina 161: 41-52.

Wirth WW, Gressitt JL (1967) Diptera: Chironomidae (Midges). In: Gressitt JL (Ed.) Entomology of Antarctica, vol. 10, Antarctic Research Series. American Geophysical Union, Washington, 197-203. https://doi.org/10.1029/AR010p0197

\section{Records from other data published in GBIF}

Hårsaker K, Aspaas AM, Dolmen D, Ekrem T, Munkeby TB, Stur E, Frode Ø, Aagaard K, Finstad AG (2020) Terrestrial and limnic invertebrates systematic collection, NTNU University Museum. Version 1.290. NTNU University Museum. Occurrence dataset. https:// doi.org/10.15468/fsreqb [accessed via GBIF.org on 02.10.2020]

The International Barcode of Life Consortium (2016) International Barcode of Life project (iBOL). Occurrence dataset. https://doi.org/10.15468/inygc6 [accessed via GBIF.org on 02.10.2020] 